\title{
O enigmático olhar do outro sobre si mesmo: Notas sobre o livro $O$ estranho, de Oswaldo de Camargo
}

Elen Rodrigues Gonçalves Edimilson de Almeira Pereira

“- Mas, que importa tudo isso?! Qual é a cor de minha forma, do meu sentir? Qual é a cor da tempestade de dilacerações que me abala? Qual a de meus sonhos e gritos? Qual a de meus desejos e febre? (Cruz e Souza)

Por isso deito-me e aspiro a poeira dos teus pés, ó mundo, Que me pisas e és meu amigo...!" (Oswaldo de Camargo)

\section{O sujeito-poeta emparedado}

A citação de um fragmento de "Emparedado", composição que encerra o livro Evocações, de Cruz e Souza, e inicia a obra O Estranho (1984), de Oswaldo de Camargo, publicitário, jornalista, ex-seminarista, nascido em 1936, em Bragança Paulista (SP), contém uma mensagem que, entre outros aspectos, aponta um significativo diálogo entre os dois autores, bem como uma linhagem poética reveladora dos conflitos entre as identidades marginalizadas e os mecanismos de repressão da sociedade brasileira.

Por um lado, no texto de Cruz e Souza, vislumbramos uma voz que murmura ao poeta, ou a nós leitores, e se constitui o seu/nosso "duplo eu", que evidencia o drama do sujeito negro que ansiava por livrar-se das amarras da sociedade, marcada por preconceitos e discriminações; por outro lado, a obra poética de Oswaldo de Camargo, herdeira dessa perquirição, representa um protesto específico, embasado na proposta do 
diálogo, aliando-se às demais formas de protesto contra a opressão. O presente artigo pretende, portanto, revelar como a poética de Camargo esboça um convite à paz, à comunhão, uma vez que o "estranho" apresentado por ele quer ser reconhecido na verdade como um irmão, um semelhante.

O conjunto de poemas que formam o livro $O$ Estranho veio a lume na década de 1980 - quase noventa anos depois da publicação de Evocações - denunciando a persistência de uma situação social francamente desfavorável aos negros brasileiros. Por meio de práticas de exclusão forjadas no passado escravista e revigoradas no presente do mundo capitalista, a sociedade brasileira insistia em não reconhecer a efetiva participação de negros e negras como cidadãos plenos. Os baixos índices de escolaridade e os altos índices de criminalidade são apenas dois, entre outros inúmeros dados desfavoráveis, que demonstram a precária condição de boa parte dos negros na sociedade brasileira.

Nunca é demais recordar que o Brasil foi o último país da América do Sul a abolir a escravidão. E mesmo após o processo abolicionista, nossa sociedade não hesitou em adotar políticas e práticas que dificultaram a inserção social dos ex-escravos e de seus descendentes. A adoção de um viés pretensamente interessado na causa de inserção social dos negros evidenciou-se através da propaganda da democracia racial e de um discurso diplomático conciliatório, responsável pela não abordagem ou pela amenização dos conflitos étnicos no país (Augel, 2010). A literatura de Oswaldo de Camargo, assim como a de outros poetas seus contemporâneos, engajados na denúncia do racismo oficial, torna-se uma literatura de resistência, questionadora dos discursos implementados por grupos dominantes.

Embora Oswaldo de Camargo participe ativamente do movimento negro, embora seja um dos fundadores dos Cadernos Negros (veículo voltado para a publicação de 
escritores afrodescendentes) e embora seja um dos criadores do Quilombhoje (grupo de discussão e aprofundamento da cultura afrobrasileira na literatura), nota-se por meio da sua poética que a busca por uma identidade individual e coletiva não se esgota no âmbito do reconhecimento de suas origens étnicas. Camargo alimenta um verbo poético permeado pelas tensões que decorrem dos questionamentos acerca de sua identidade fragmentária, forjada a partir de elementos contrastantes, ou seja, do chamado da ancestralidade afrodescendente e da afirmação de um sujeito formado num ambiente de educação "branca". Diante disso, Moema Parente Augel afirma que,

en ningún otro escritor negro más que en él se observa tan profunda y desgarradoramente la contradicción de vivir entre dos frentes, la angústia de la delimitación, de la alienación, la doble pertenencia, la solidaridad y la búsqueda de uma identidade personal y colectiva (2010, p. 182).

Considerando as tensões acima mencionadas, cujos efeitos permeiam o fazer poético de Oswaldo de Camargo, lançamos um olhar sobre sua trajetória pessoal entrelaçada ao contexto histórico que, embora o aparelhasse para a vida intelectual, acaba por conferirlhe uma aura de sujeito exilado, ou melhor, de sujeito que, dentro de sua própria sociedade, experimenta a sensação de não pertencimento identitário e ou territorial.

\section{A realidade cruel em $O$ estranho}

A expressão "das Unheimlich", termo usado por Freud (1919) em um artigo de mesmo nome e do qual derivaram os respectivos significados dos termos "estranho", 
“inquietante" e "misterioso", abrange uma perspectiva sobre tudo aquilo que nos causa estranheza e que, por nos ser desconhecido, nos suscita o medo. Em confluência, a palavra "heimlich" sugere certa ambiguidade, uma vez que o termo enuncia ao mesmo tempo algo que é familiar, doméstico e íntimo, como aquilo que está oculto e reprimido. O contraponto surge na medida em que "o que é aterrorizador, assustador, no mais das vezes, habita o familiar e esse estranho, ou esse sinistro, pode ser o que esse sujeito desconhece de si mesmo" (Marquêa, 2007, p. 61)

O efeito do unheimlich é produzido na obra de Oswaldo de Camargo na medida em que o poeta trata dos afetos humanos (dos afrodescendentes, em particular), dos "assombros" vividos, dos enigmas da morte, do encontro com o diferente e com o outro em nós mesmos, instaurando a sensação do estranho em nosso íntimo. Semelhante à imagem refletida em um espelho é a estranheza que o sujeito experiencia no momento em que se vislumbra o encontro com algo que, mesmo aparentemente desconhecido, é a própria imagem refletida: o eu e seu outro eu figuram o mesmo ser.

De maneira sutil, essa sensação se explicita como uma das grandes provocações da lírica de Oswaldo de Camargo, na medida em que confronta os brasileiros, em geral, e os afrobrasileiros, em particular, com um processo de identidade em crise. Ou seja, se, por um lado, os discursos dominantes negaram identidade aos afrodescendente, e se, por outro, os afrodescendentes afirmaram sua identidade a partir das heranças das matrizes africanas, vale dizer que o poeta rasura essas duas perspectivas.

Por meio de seu lirismo tenso e trágico, Camargo demonstra que as possíveis identidades dos afrodescendentes desenham-se, de fato, como algo ainda não bem delineado e não tão bem reconhecido, como se imagina na sociedade brasileira. A lírica de Camargo é, portanto, erguida a partir da dúvida e da indagação no que tange à formulação dos processos identitários dos afrodescendentes no Brasil. 
Por esse viés, é possível compreender que a citação de Cruz e Souza revela uma condição na qual o emparedado encontra-se enclausurado e sufocado pelos muros de uma sociedade regida pelo ideário de grupos étnicos superiores e inferiores. Dentro desse cenário complexo, é possível vislumbrar um fenômeno de "resistência cultural pelo qual o drama de uma existência, que é subjetivo e público, ao mesmo tempo, sobe ao nível da consciência inconformada e se faz discurso [...] na história objetiva da cultura" (Bosi 2002).

O muro que se ergue em torno do indivíduo negro e que o sufoca pode ser percebido em contrapartida por outro viés: aquele que "protege" a sociedade da realidade, ou seja, dos aspectos contraditórios que a constituem e que, uma vez revelados, podem abalar os alicerces dos status quo. Em outras palavras, é mais fácil manter as aparências e negar que o "Emparedado é, dilaceradamente, o corpo que vive sob o império da carne, do sangue, da raça, e entre os muros de uma sociedade que é pura réplica da selva darwiniana" (Bosi 2002).

Se a filosofia é considerada "uma teoria do real", visto que ela resulta de um olhar interpretativo, interrogatório, mesmo criativo, sobre as coisas, a atividade filosófica, por sua vez, julga que as "coisas são verdadeiras em seu detalhe", mas "duvidosas em seu conjunto" (Rosset, 1989). Isto é, um fato pontual pode ser considerado real, ao passo que um conjunto de fatos que compõem a realidade é incerto, donde se pode concluir que só há realidade particular e não realidade genérica.

Segundo Clément Rosset, em O princípio de crueldade (1989), a realidade, ainda que seja ininteligível, não é irreal. Isso significa que a dificuldade de se acreditar na inteireza da realidade do real não está apenas no fato de ser a realidade incompreensível, mas principalmente pelo fato de ela ser dolorosa e cruel. Mais adiante, em sua obra, Clément deixa claro que por "crueldade" do real ele entende como "a 
natureza intrinsecamente dolorosa e trágica da realidade" (1989, p. 17), que carrega em si seu caráter único e consequentemente inapelável. Diante disso, Rosset nos afirma ser a realidade não apenas horrível, mas triste:

Uma verdade triste é, ao mesmo tempo, e por cúmulo de infelicidade, uma verdade verdadeira - ou ainda, o que quer dizer o mesmo, que uma realidade penosa é também, e por cúmulo de crueldade, uma realidade real. Em outras palavras - e é justamente o que eu queria sugerir, evocando a dupla crueldade do real -, parece que o mais cruel da realidade não reside em seu caráter intrinsecamente cruel, mas em seu caráter inelutável, isto é, indiscutivelmente cruel (Rosset, 1989, p. 19).

Nesse sentido, se o homem é incapaz de aceitar a realidade, posto que essencialmente trágica e dolorosa, Oswaldo de Camargo, em sua obra poética, convida-nos, por sua vez, a observar a realidade de um ponto de vista particular para que conheçamos as marcas de sua história e reconheçamos, portanto, do que é feita a literatura negra, ou seja, um misto das experiências particulares da persona negra, que se converte em eu poético quando travestida em poesia, revelando-nos assim suas angústias, suas vivências em uma sociedade canonicamente branca. Em "Rumo" (Camargo, 1984, p. 21), segundo poema do volume $O$ estranho, o eu poético questiona as ações de Deus, particulamente o deus judaico-cristão, em cuja linhagem se inseriu a formação de fé do poeta:

Às vezes ergo os olhos, interrogo

o seco céu sem urubu, sem nódoa

de nuvem: Deus, 
que queres?

Que eu me atropele

com a minha própria sombra, que embranqueça

meu dorso e voe?

Em "Rumo", adquire relevo o questionamento a Deus a partir da perspectiva crítica do eu poético, que não se conforma em embranquecer-se. Embora saiba que pertence a uma cultura híbrida, articulada através das relações e conflitos entre a ancestralidade africana e as heranças ocidentais, o poeta vive um conflito de identidade, que o leva a colocar em xeque as diferentes matrizes culturais que o forjaram. Um dos resultados desse embate é a sensação de desconforto e inquietação que afeta o sujeito e o mergulha no emaranhado de indagações: "que queres/ Que eu me atropele...?".

A realidade, aqui, se configura amarga e cruel. A aceitação do indivíduo negro na sociedade culturalmente branca acompanha a incapacidade de compreender a realidade real e aceitá-la, como se a realidade (vista como única e suficiente) não se bastasse a si mesma ultrapassando, desse modo, a faculdade humana de compreensão e de sentir-se afetado pelo real (Rosset, 1989). O autor, portanto, reitera:

a realidade é cruel por natureza, mas também, e por uma espécie de último refinamento de crueldade, verdadeiramente real. [...] Não somente a verdade é horrível, [...] mas alem disso é verdade que ela o seja - ela é efetivamente horrível. [...] Uma verdade triste é, ao mesmo tempo, e por cúmulo de infelicidade, uma verdade verdadeira - ou ainda, o que quer dizer o mesmo, que uma realidade penosa é também e por cúmulo de crueldade, uma realidade real. Em outras palavras - e é 
justamente o que eu queria sugerir, evocando a dupla crueldade do real -, parece que o mais cruel da realidade não reside em seu caráter intrinsecamente cruel, mas em seu caráter inelutável, isto é, indiscutivelmente cruel. (Rosset, 1989, p. 18-19)

Voltando ao poeta, nota-se que a inserção e a consequente aceitação do indivíduo afrodescendente nesse tipo de sociedade só se faz diante do seu "embranquecimento" intelectual e psicológico, criando um conflito no qual o sujeito negro por se impor, mas, para isso, precisa negar uma parte considerável dos elementos constituintes de sua identidade. Esse conflito nutre a poética de Camargo, tal como demonstra o poema "A escolha" (1984, p. 32):

Eu tenho a alma voando

no encalço de uma ave cega:

se escolho o rumo do escuro

me apoio à sombra do muro

pousado na minha testa.

Se elejo o rumo da alvura

falseio os passos da vida

e me descubro gritando

um grito que não é meu.

Que faço das mãos cobertas

de um sol doído só de África?

E do tantã nestas veias, turbando o ritmo ao sangue? 


\begin{abstract}
Na face o dia não pousa
o seu cesto de alegria

e a manhã precipita

ventos e noites amargas.
\end{abstract}

Se notarmos o período em que a obra foi produzida, ou seja, a segunda metade do século XX (período marcado ainda pelas sombras da ditadura Vargas e da posterior ditadura militar de 1964, mas também pelas influências das lutas pelos direitos civis nos Estados Unidos, entre outros acontecimentos nacionais e internacionais importantes), é possível reconhecer que a poética de Camargo apresenta uma voz negra representante de uma consciência em formação que se assume em meio ao mundo branco tendo, portanto, como uma de suas marcas, a tensão dos embates e o apelo à construção das utopias identitárias dos afrobrasileiros.

Sabe-se também que, nessa época, e ainda hoje, por trás de uma linha de comportamento - em que o indivíduo negro se vê obrigado a adaptar-se aos padrões de comportamento social e de tendência cultural que lhe são exigidos e, a despeito da adaptação de uma "mentalidade branca", é muitas vezes desqualificado pela questão da cor da pele -, existe uma linha de cor que é ainda mais cruel, posto que o negro é transformado em estereótipo sob olhar do branco (Brookshaw, 1983, p. 187).

É, pois, em meio às turbulências geradas pela repressão étnica e social e pelas atitudes de resistência à opressão que se desenha a poética de Oswaldo de Camargo. Entre a necessidade de responder de modo objetivo a essa demanda (por meio de uma poética politicamente engajada) e de modo não menos objetivo, porém firmado sobre a consciência de que a literatura é, também, criação estética, Oswaldo de Camargo 
articulou seu discurso poético como ponte entre as exigências sociais dos afrodescendentes e os apelos dessa mesma comunidade para forjar maneiras de expressão poética capazes de apresentarem, simultaneamente, os traços específicos dessa comunidade e os traços fundantes de uma experiência lírica universal.

Em seu artigo intitulado "Hibridismo e tradução cultural em Bhabha", Lynn Mario T. Menezes de Souza (2004) afirma que "no processo relacional da constituição de identidades, a alteridade do branco constitui o negro tanto quanto a alteridade do negro constitui o branco" (p. 120), instaurando-se o hibridismo no seio da identidade. Se, para Bhabha, o conceito de cultura é híbrido, dinâmico e tradutório, ele se liga, por sua vez, à sobrevivência dos seres, quando os deslocamentos aguçam as diferenças culturais. Desse modo, colonizado e colonizador participam de enredo dramático, no qual se constrói uma imagem de um sujeito legitimado cujo objetivo consiste em estabelecer a dominação desse sujeito sobre o outro, aquele cuja identidade não é reconhecida (Bhabha, apud Souza, 2004, p. 121). Desse modo, pensar o processo de construção da identidade pela perspectiva do hibridismo de Bhabha provoca, do ponto de vista imagético, a criação de uma espécie de máscara, na tentativa de se camuflar a diferença, a ausência ou o estranho.

Promove-se, dessa maneira, um processo de estereotipia, no qual se pretende negar a multiplicidade em nome de se assegurar uma unidade cultural. Em "Bilhete" (1984, p. 53), Oswaldo de Camargo declara seu sentimento de solidão e orfandade em meio a uma sociedade que não lhe oferece muitas opções para expressar-se, uma vez que se sente estranho na terra em que habita. De modo dramático, o poeta revela que não se sente reconhecido como irmão em sua terra de origem. Por isso, o poema funciona como um lugar de compensação, que minimiza o sentimento de orfandade do 
sujeito; resta, pois, a este sujeito sem lugar, exilado, lembrar-se de suas raízes étnicas, de base africana, em busca de algum reconhecimento íntimo:

Meus pés, como casca, rescendem a raízes

e um afro vento me ronda.

O ressequido céu, sem ave, muda-me

a cor do roto em aço.

Com ele corto, sem ele volto

de minha andança pela cidade.

Sou bem solitário e meu riso

pouco tem a ver com minha raça.

Procuro, sim, o pensamento em fogo

que meus pais largaram

na sua última

fuga. Um pensamento em fogo...

Buscam-me ainda

crocodilos, e a mosca

tsé-tsé jamais saberá

que aqui me acho:

a oito mil, trezentos e trinta quilômetros

da costa d'África...

Sou bem solitário e meu nervoso gesto

nada tem a ver com a minha raça.

(Simples rotação do mundo a acelerar-me as juntas, a adestrar-me à corrida que me salve). 
Meu cabelo afro, também,

pouquíssimo tem a ver com a minha raça.

Contam, porém, sobre nós muita coisa

só possível, amiga, de se explicar no escuro...

Se, por um lado, o poeta canta um retorno espiritual à sua terra mãe, por outro, ele se mostra temeroso e angustiado porque acredita que não pertence a lugar nenhum. Desse modo, o poeta arrisca-se numa investigação que o conduza a uma possível identidade ancestral, na qual ele pressupõe encontrar elementos que lhe digam quem ele é. Nesse ponto, vale considerar as análises de Moema Parente Augel acerca da ruptura que assombra a construção das identidades tecidas na diáspora africana. Segundo Augel, textos como o poema acima, de Oswaldo de Camargo, revelam-nos a complexa experiência dos afrobrasileiros gerada pela "consciência de que sua fidelidade e seu apego ao continente de origem não são nem conhecidos nem correspondidos" (2010, p. 196).

\section{Outra Canção}

Oswaldo de Camargo finaliza a coletânea $O$ estranho com uma série de poemas que integram a seção "Canções". Nessa etapa, o poeta declara que "por ora cantaremos dores velhas, que as novas vêm chegando devagar..." (1984, p. 67). Considerando o encontro do apuro estético com expressão de determinados fatos sociais na poética de Oswaldo de Camargo, verificamos que o equilíbrio dessas duas instâncias alimenta uma voz poética que é, simultaneamente, retrato de uma experiência individual e de uma vivência coletiva: ou seja, onde soa voz do eu ressoa também a voz de uma comunidade, 
nesse caso, a comunidade humana em sentido amplo, para além das fronteiras de identidades étnicas ou nacionais. A voz poética que detecta indícios de sofrimento e desamparo, de espoliação e injustiça, tal como no poema "Antigamente" (Camargo, 1984, p. 69), remete tanto à agonia dos afrodescendentes quanto à agonia que se impõe a todo e qualquer ser humano privado de sua liberdade.

Como quem quer cantar, mas não canta, como quem quer falar, mas se cala, eu venho fazendo escala no porto de muita mágoa.

Antigamente eu morria, antigamente eu amava, antigamente eu sabia qual é o chão que resvala se o passo da gente pesa. Hoje que sou um homem leve, sem dinheiro, sem altura, e tenho a boca entreaberta, olhando o incêndio do mundo, vejo a certeza mais certa: eu estou cavando no fundo! $[\ldots]$ 
Como podemos perceber, o particular e o universal entrecruzam-se nas linhas do poema acima e em parte expressiva dos demais poemas de Camargo. Isso evidencia que o poeta entrelaça de maneira equilibrada e eficiente as demandas das questões sociais com a preocupação de exprimi-las com apuro estético. Imerso, pois, em suas indagações pessoais e, também, naquelas que afetam o ser humano em estado de risco, Oswaldo de Camargo prepara-se para vir à tona e representar na linguagem do poema essas indagações. Aí, nesse espaço de linguagem viva, o poeta transcende suas dúvidas e experiências para abrir-se ao mundo como um ser humano entre outros, vivendo relações de encontro e desencontro.

Paul Valéry acredita que "um poeta não tem como função experimentar o estado poético: essa é uma questão particular. Tem como função criá-lo nos outros" (apud Dufrenne, 1969, p. 101). Dessa forma, o estado poético é esse estado de encantamento provocado pelos poderes do verbo, no qual a consciência se desdobra para transfigurar fatos limitados em sensações ilimitadas. Eis o que realiza Oswaldo de Camargo aos nos apresentar o deslocamento do afrodescendente não só como um fato estritamente histórico, mas, de modo profundo, como uma dura experiência humana. Experiência esta que se traduz em poéticas do exílio e da fragmentação, da violência e do desespero, da utopia e da resistência, poética, enfim, da vida que Camargo, como tantos outros poetas, resgata e protege.

Dessa maneira, o estado poético em que o poeta se encontra e através do qual sente opera e realiza não se consubstancia em uma abstração irreal e quimérica. Ao contrário, acontece em um mundo onde está presente o real. Em “O poético" (1969), Dufrenne acredita que essa presença do ser poético no poeta é conciliada pela comunicação com o ser poético da Natureza, uma vez que ela o inspira e provoca a espontaneidade do poeta que responde ao apelo da mesma. $\mathrm{O}$ autor ressalta ainda que $\mathrm{o}$ 
poeta cria nos outros (leitores), sem circunscrever-se a si mesmo, o estado poético. Aberto e predisposto ao estado poético pela Natureza, o leitor encontraria na obra a realização daquilo que apenas percebeu ou sentiu, mas não conseguiu fixar concretamente pela linguagem.

Assim, o leitor permanece como virtualidade ou disposição frente à obra poética e deverá assumir diante dela uma atitude de humildade para escutar a sua mensagem. Dessa maneira, pensamos, pode ser lido com maiores ganhos o livro O Estranho. O leitor atento e aberto às provocações que Camargo lhe apresenta através do verbo poderá perscrutar a voz da poesia e reconhecer a si mesmo na linguagem poética, bem como certa experiência histórica e social nela incutida.

Na primeira seção de O Estranho, cujo título é o mesmo do livro, Oswaldo de Camargo insere um pequeno poema chamado "Fragmento número 2" (Camargo, 1984, p. 65), no qual indaga não a Deus, como em "Rumo", mas, dessa vez, ao mundo a sua volta e aos "sóis passados", o que agora o espera nas horas sombrias em que não há mais luz. Essa abertura da indagação - cuja resposta interessa aos seres humanos de boa vontade, como um todo - demonstra que o livro O Estranho é uma obra de denúncia, de protesto contra um apartheid ideológico, e também uma obra atravessada por questões metafísicas, que ultrapassam os limites da historicidade.

Desse modo, além de aludir ao engajamento político-social - tão marcante na obra de poemas afrodescendentes como Solano Trindade, Cuti, Paulo Colina, Márcio Barbosa, entre outros - o discurso poético que fundamenta $O$ Estranho convida-nos à reflexão sobre os duros temas que evidenciam as desigualdades sociais. Por ser o convite a uma reflexão dolorosa e profunda, esse livro em particular revela-nos um autor ciente das restrições da poesia em face da enormidade dos desafios a serem superados pelos indivíduos situados em condições desfavoráveis. Apesar disso, 
Camargo insiste: "eu vos convidei, senhores!/ Provai, provai do meu pão!” (Camargo, 1984, p. 20). Com esse gesto de doação e solidariedade, o poeta aponta para a possibilidade de criarmos a comunhão entre as diferentes identidades, ainda que as arestas continuem a ameaçar a convivência fraterna, particularmente, nas sociedades que herdaram, e ainda não ultrapassaram de todo, os conflitos gerados pelos antigos sistemas coloniais.

\section{Referências Bibliográficas}

Augel, Moema Parente. "Poesía negra: la poesia afrobrasileña de la época actual". In: Edimilson de Almeida Pereira (org.). Um tigre na floresta de signos: Estudos sobre poesia e demandas sociais no Brasil. Belo Horizonte: Mazza Edições, 2010, p. 168- 186.

"Geografias imaginárias: África na poesia afro-brasileira contemporânea". In: Edimilson de Almeida Pereira (org.). Um tigre na floresta de signos: Estudos sobre poesia e demandas sociais no Brasil. Belo Horizonte: Mazza Edições, 2010, p. 187- 212.

Bosi, Alfredo. Poesia versus Racismo. Instituto de Estudos Avançados da Universidade de São Paulo. Vol. 16. No.44. São Paulo. Jan/ Abril. 2002. Disponível: http://www.scielo.br/scielo.php?pid=S0103-40142002000100015\&script=sci_arttext. Acesso: 09/abril/2013.

Brookshaw, David. Raça E cor na literatura brasileira. Trad. Marta Kirst. Porto Alegre: Mercado Aberto, 1983.

Camargo, Oswaldo de. O Estranho. São Paulo: Roswitha Kempf/ Editores, 1984.

Ceia, Carlos. Inquietante Estranheza (Das Unheimlich). Disponível: http://www.edtl.com.pt/index.php?option=com_mtree\&task=viewlink\&link_id=428\&Ite mid=2. Acesso: 30/abril/2013.

Dufrenne, Mikel. O poético. São Paulo: Globo, 1969.

$3^{\text {RASILIANA- Journal for Brazilian Studies. Vol. 4, n.2 (2016). ISSN 2245-4373. }}$ 
Marquêa, Vera. Sobre "Das Unheimlich", de S. Freud. Revista ECOS, julho 2007, edição n.005. p.61- 63. [http://www.unemat.br/revistas/ecos/docs/v_05/61_Pag_Revista_Ecos_V-05_N-02_A2007.pdf]. Acesso: 3 de Março de 2015.

Rosset, Clément. O princípio de crueldade. São Paulo: Rocco, 1989.

Souza, Lynn Mario T. Menezes de. Hibridismo e tradução cultural em Bhabha. In: Abdala Junior, Benjamin (org). Margens da cultura: mestiçagem, hibridismo \& outras misturas. São Paulo: Boitempo Editorial, 2004. P. 113-133. 